\title{
Cloud based Testing Techniques (CTT)
}

\author{
Akash Shrivastva \\ CSE Dept. DIT University \\ Dehradun, INDIA
}

\author{
Shubham Gupta \\ IT Dept. DIT University \\ Dehradun, INDIA
}

\author{
Rinki Tiwari \\ IT Dept. DIT University \\ Dehradun, INDIA
}

\begin{abstract}
Cloud computing is the recently emerged technology which has gained popularity among organizations and corporates. For better services of the cloud, there is need for some kind of testing. Cloud testing then came into existence which referred as a form of testing in which cloud computing environment is used by web applications to simulate real world user traffic. Testing somehow saves the cost of maintenance which is helpful for the customers. This paper provides us with various cloud testing techniques, challenges, issues and benefits in testing areas. It also elaborates all the fundamental concepts regarding features and requirements in cloud testing. Furthermore, various cloud testing platforms are also discussed briefly. Cloud testing has been explained widely in this paper that would help to understand various aspects of cloud testing in a much better way.
\end{abstract}

\section{Keywords}

Cloud Testing, Cloud computing, Testing, Cloud forensics.

\section{INTRODUCTION}

Cloud testing is a form of testing in which cloud computing environment is used by web applications to simulate real-world user traffic [1]. It uses the concept of cloud and $\mathrm{SaaS}$ (Software as a service). Cloud testing helps for testing the cloud by the support of cloud infrastructure. This concept of testing a cloud tends to validate and verify applications, environments and infrastructure of cloud computing model. Cloud testing is also defined as TaaS i.e. testing as a service which is used for testing various products and services associated with cloud [2]. It also refers to testing of cloud based applications by using resources as hardware, software and infrastructure. Cloud testing in some or the other way boosts the competitiveness of organisation and testing costs. Cloud testing is gaining popularity due to reduce costs, speed and better quality of the applications. Services provided by cloud testing: [3]

1. TaaS Management

2. Test Environment Management

3. Test Management

4. On-Demand Testing

5. Test Simulation

6. Performance \& Scalability Testing

Some cloud testing elements are: [4]

1. Relevant testing types are identified

2. Challenge analysis is done

3. Cloud testing environment is setup

4. Right testing strategy is selected

In this paper, research focus only at giving discussion about the cloud testing i.e. all its basic concepts as its scope, elements, features, benefits, challenges etc.

The remaining paper has been divided into further sections. In section 2, we will discuss the various cloud testing techniques. In section 3, benefits of cloud testing are explained. Further various cloud testing platforms are discussed in section 4 . In section 5, challenges are discussed briefly. Finally we conclude our paper in section6.

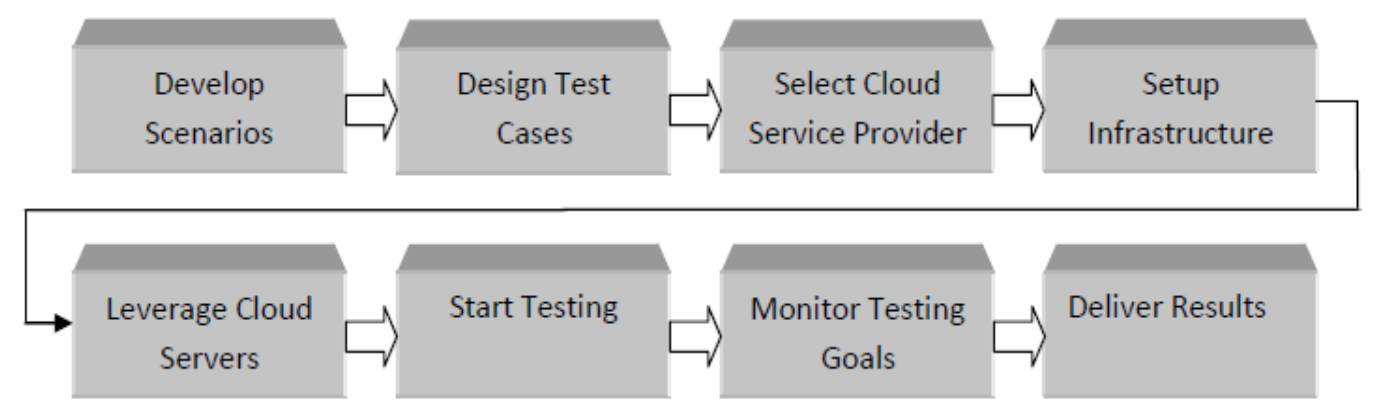

Fig 1: Cloud Testing Life Cycle [5] 


\section{TYPES OF CLOUD TESTING TECHNIQUES}

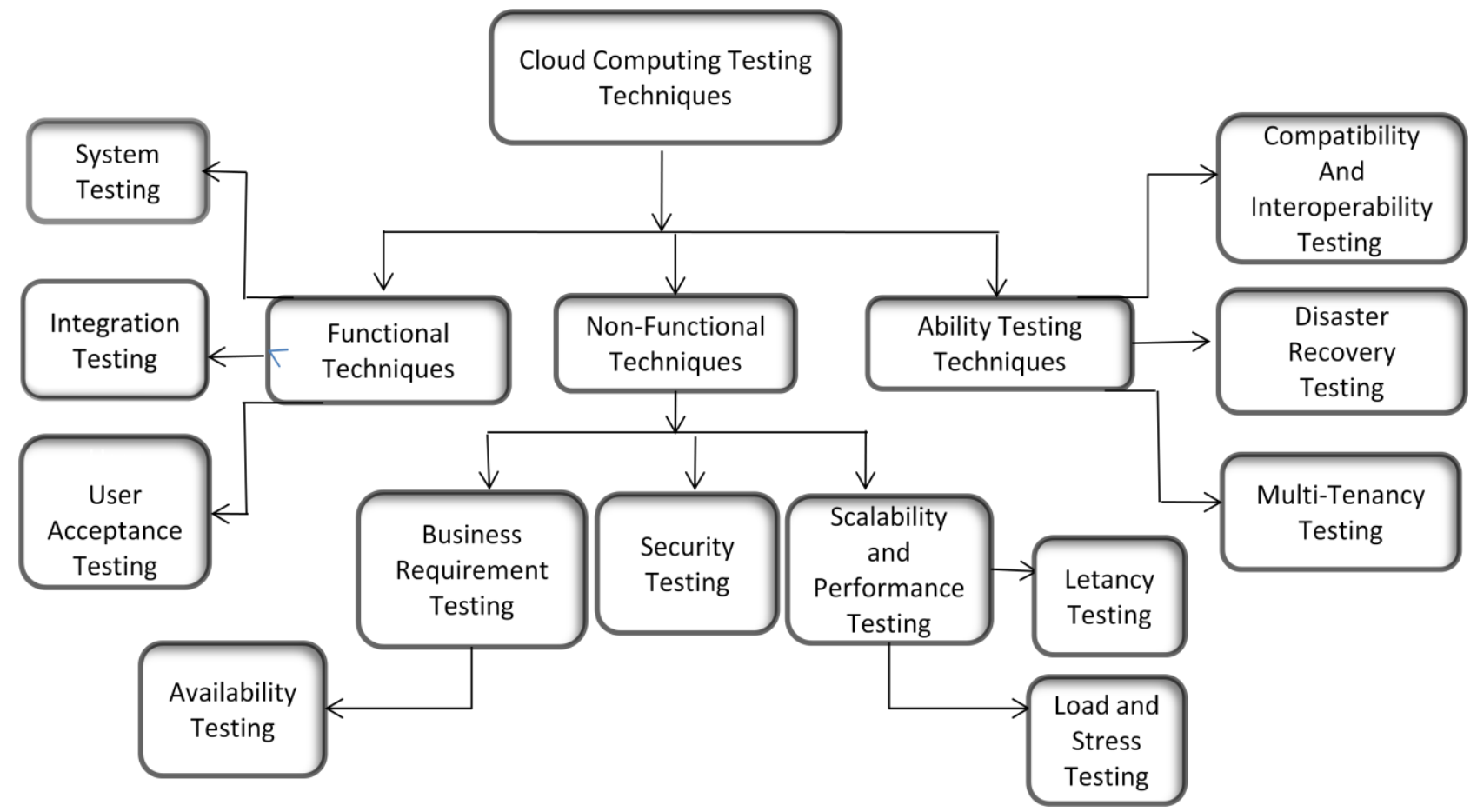

Fig 2: Cloud Testing Techniques types

\subsection{Functional Testing Techniques}

Functional Testing is a process of quality assurance [6]. It is performed for both remote and local applications. It is used to test all the features and functions of a system which includes software and hardware [1,2].

Functional testing involves carrying various tasks and comparing the result of same tasks with the expected output. Functional Testing can be performed both manually and automatically with a human tester or software program respectively [7]. Functional Testing usually describes what the system does.

\subsubsection{System Testing}

System testing is a testing performed on a fully integrated system to evaluate the system's compliance with its specified requirements. It is performed in the context of a Functional requirement Specification(s) (FRS) and/or a System Requirement Specification (SRS) on the entire system. System testing tests the behaviour, design and the expectations of the customer [8].

\subsubsection{Integration Testing}

Integration testing is the technique in which each software module is tested as a group. It fits cloud computing system in the context of overall business strategy. Integration of cloud becomes necessary for business and enterprise that adopts a cloud based solution that requires integration of data and interface in the cloud with on-demand application. It is mainly responsible for connecting source and target system, extracting data from source system, mediating semantics and syntax of data and publishing the data to target system [9].

\subsubsection{User Acceptance Testing}

This testing is done to verify the current provided cloud solution from the vendor [10]. In this testing, business requirements are used to prove that the Cloud solution that is delivered meets certain needs [11].This testing is done on both off-premise and on-premise. Immediate control and monitoring of test progress is allowed by onsite testing [2].

\subsection{Non-Functional Testing Techniques}

This testing is done for ensuring that a web application meets the specified performance requirements. It is also known a performance testing technique.

It is done against the non-functional requirements which reflect the quality of the product. It has a great influence on customers.

\subsubsection{Business Requirement Testing}

Organisations should carefully, precisely examine their business requirements before migrating their business to a cloud computing solutions this is because business requirements are the building blocks for cloud computing solutions. The business requirements can be achieved by the reviews, workshops and meetings [11].

\subsubsection{Cloud Availability Testing}

This ensures that cloud services must be available at all times .There should be no downtime which could adversely affect the business of client $[11,12]$. 


\subsubsection{Cloud Security Testing}

It has become one of the important parts of testing as security issues as increasing gradually in business. It is helpful as it assures that business data is stored and transported safely. For identifying access methods to a system by using some tools and techniques used by the hackers can guarantee security of cloud solutions $[11,13]$.

In a cloud environment, network security is most important. Several security appliances are in widespread use, which protects enterprises and data centres. These devices encourage the roles of intrusion prevention systems, firewalls, anti-virus, anti-spam, and data loss prevention. Security mechanisms are tested in three dimensions: Accuracy, Effectiveness and Performance.

\subsubsection{Cloud Scalability and Performance Testing}

Cloud Scalability is that area of concern where proper amount of testing is needed. Cloud Computing solutions are always scalable on demand. Cloud scalability and Performance testing techniques helps us to measure the cloud systems performance accurately and carefully [11]. Performance testing is responsible for finding out thresholds, bottlenecks \& limitations [13]. Hence, Performance testing is the testing which measures response times and issues related to specific actions while system is subjected to increasing load from different multi user operations. It determines the capacity, responsiveness, reliability, throughput, and/or scalability of a system under a given workload. It Can Assess production readiness, Evaluate performance criteria, Find system capacity, Compare performance characteristics of multiple systems, Find the source of performance problems, Support system tuning, Find throughput levels.

\subsubsection{Cloud Load and Stress Testing}

Load testing is used for creating heavy user traffic and measuring its response. It also tunes the performance of any application to meet certain standards. On the other hand, Stress Testing helps to determine ability of application to maintain a certain level of effectiveness [13,14]. For any application, it is essential to work even under excessive stress and maintain stability. Stress testing does this by creating peak loads using simulators.

\subsubsection{Latency Testing}

This testing involves measuring the latency (delay) between the action and the response for any application after deploying it on cloud [11,13].

\subsection{Ability Testing Techniques}

Ability testing is done to ensure that user receives appropriate services from cloud environment on demand. Under this category, Compatibility and Interoperability Testing, Disaster Recovery Testing, Multi-Tenancy Testing is performed [2].

\subsubsection{Compatibility and Interoperability Testing}

It is a testing performed on the application to evaluate the application's compatibility with the computing environment. A cloud application must be capable to work across various environments and executed on various cloud platforms. Hence, it is easier for migration of cloud application from one infrastructure to another [15].
A compatibility test includes:

1. Hardware configurations

2. Different Platforms

3. Computer Peripherals

4. Network Environment [7].

\subsubsection{Disaster Recovery Testing}

Disasters are an inevitable certainty for any organization, but while inevitable, disasters are also generally unpredictable. The service provider of cloud prefers that its cloud services must be available to users all the time .Disaster recovery time must be low after some failure occurs. This testing is done to ensure that the cloud services must be available to user after some failure occurs, with minimum or no data loss [16].

\subsubsection{Multi-Tenancy Testing}

Multi-tenancy refers to a principle where a single instance of the software runs on a server, serving multiple clientorganizations. It refers to multiple organization and clients using an on demand offering. The offering should be customizable for each client and should provide data as well as configuration level security to avoid any access related issues [17].

\section{BENEFITS OF CLOUD TESTING}

Cloud testing helps business in setting and maintaining the environments, On-demand services, lower cost, resource pooling, elimination of capital expenditure in advance, and broader network access, rapid elasticity and reduction in cycle reduction time for different business offering in this dynamic and fast going services and IT industry.

Below are some of the key benefits with regards to Testing in cloud.

1. Rapid provision of Test environment(s) - Due to the dynamic nature of the real world application in terms of Requirements and user in short period of time, it's very difficult for many companies to set up infrastructure for testing use. With the Help of Cloud, it's very easy for the organization to turn up the testing environments to fulfil project time lines. Test replica of production environment can be simulated by business/users which help testing team to validate the business scenarios and finding bugs at earliest.

2. Reduced capital expense - Cloud will take care for setting up for the testing infrastructure as when needed by the organization and decommission all the set up /servers once the testing is done which helps companies to save their money. This helps many companies to get the work done in a lower price as compared to earlier as there is no cost associated with them in setting up that entire infrastructure in advance.

3. Rapid customization of hardware resources -As Companies are allowing cloud environment for their testing, it's easy for organization to simulate the production scenarios to verify the Load, performance testing, verifying the scenarios in different environment with multiple browsers in different operating system and latest versions available in market. 
4. Support Green computing and Reducing Carbon foot Print- Green

5. Computing is the study of using computing resources efficiently. The global use of computing resources continues to grow dramatically due to huge IT market and different industries. As most of the companies have started adopting cloud strategy which provides infrastructure based on demand, cloud solution enables companies to become more environmentally friendly.

6. Effective use of Resources- Cloud will take care of all business need as and when required .By using cloud, server efficiency and utilization has been drastically improved through the even distribution of workload. Testing in the cloud borrowed the existing cloud computing infrastructure provided by the vendor which helps in reducing the cost of computing to a great extent with increasing testing effectiveness in the process [10]

\section{COMPARISON AMONG VARIOUS CLOUD TESTING TECHNIQUES AND PLATFORMS}

Following are the comparisons and various cloud testing platforms which are considered to be the key players in the cloud testing zone. These are the leading cloud testing providers as per the five categories: infrastructure, platform, security, storage and software.

Table 1. Comparison Between different testing techniques [1]

\begin{tabular}{|c|c|c|c|c|}
\hline Test type & Testing focuses & $\begin{array}{l}\text { Cloud/SaaS Oriented } \\
\text { Testing inside a Cloud }\end{array}$ & $\begin{array}{l}\text { Online Application-Based } \\
\text { Testing on a Cloud }\end{array}$ & $\begin{array}{l}\text { Cloud-Based } \\
\text { Application } \\
\text { Testing over } \\
\text { Clouds }\end{array}$ \\
\hline $\begin{array}{l}\text { Functional } \\
\text { Testing }\end{array}$ & $\begin{array}{l}\text { GUI-based and API based } \\
\text { service functions }\end{array}$ & $\begin{array}{l}\text { Testing SaaS/Cloud } \\
\text { based service functions } \\
\text { inside a cloud }\end{array}$ & $\begin{array}{l}\text { Testing online-based application } \\
\text { service functions on a cloud }\end{array}$ & $\begin{array}{l}\text { Testing cloud- } \\
\text { based application } \\
\text { service functions } \\
\text { over a cloud } \\
\text { infrastructure }\end{array}$ \\
\hline $\begin{array}{l}\text { Integration } \\
\text { Testing }\end{array}$ & $\begin{array}{l}\text { SaaS interactions and Cloud } \\
\text { connections }\end{array}$ & $\begin{array}{l}\text { Vendor-specific } \\
\text { component and service } \\
\text { integration inside a } \\
\text { private/public cloud }\end{array}$ & $\begin{array}{l}\text { Integration between online } \\
\text { clients and back-end servers on a } \\
\text { cloud }\end{array}$ & $\begin{array}{l}\text { - End-to-end } \\
\text { application } \\
\text { integration over } \\
\text { clouds Integration } \\
\text { with legacy } \\
\text { systems over } \\
\text { clouds }\end{array}$ \\
\hline Security Testing & $\begin{array}{l}\text { SaaS/Application data, } \\
\text { processes, functions, and } \\
\text { user privacy }\end{array}$ & $\begin{array}{l}\text { SaaS/Cloud security } \\
\text { features and user privacy } \\
\text { in a cloud }\end{array}$ & $\begin{array}{l}\text { User-oriented security and } \\
\text { privacy on a cloud }\end{array}$ & $\begin{array}{l}\text { System-level end- } \\
\text { to-end security } \\
\text { over clouds }\end{array}$ \\
\hline $\begin{array}{l}\text { Performance } \\
\text { \& Scalability } \\
\quad \text { Testing }\end{array}$ & $\begin{array}{l}\text { Performance and } \\
\text { scalability based on a } \\
\text { SLA }\end{array}$ & $\begin{array}{l}\text { SaaS/Cloud performance } \\
\text { and scalability testing in } \\
\text { a cloud based on the } \\
\text { given SLA }\end{array}$ & $\begin{array}{l}\text { User-oriented application } \\
\text { performance and scalability } \\
\text { testing on a cloud }\end{array}$ & $\begin{array}{l}\text { End-to-end } \\
\text { system-level } \\
\text { performance and } \\
\text { scalability } \\
\text { inside/on/over } \\
\text { cloud based on a } \\
\text { given SLA }\end{array}$ \\
\hline $\begin{array}{l}\text { API and } \\
\text { Connectivity } \\
\text { Testing }\end{array}$ & $\begin{array}{l}\text { API interfaces } \\
\text { and connectivity } \\
\text { protocols (HTTPS, } \\
\text { REST, SOAP, RMI) }\end{array}$ & $\begin{array}{l}\text { SaaS/Cloud API } \\
\text { \&connectivity testing in } \\
\text { a cloud }\end{array}$ & $\begin{array}{l}\text { Testing user-centered } \\
\text { service APIs and } \\
\text { connectivity on a cloud }\end{array}$ & $\begin{array}{l}\text { Testing } \\
\text { application } \\
\text { service APIs and } \\
\text { connectivity over } \\
\text { Clouds }\end{array}$ \\
\hline $\begin{array}{l}\text { Interoperability } \\
\text { \& Compatibility } \\
\text { Testing }\end{array}$ & $\begin{array}{l}\text { Validate different client } \\
\text { interfaces and technologies } \\
\text { and diverse compatibilities } \\
\text { on different platforms and } \\
\text { browsers }\end{array}$ & $\begin{array}{l}\text { Testing Cloud/ SaaS } \\
\text { compatibility, } \\
\text { connectivity protocols } \\
\text { and UI/client } \\
\text { technologies inside a } \\
\text { cloud }\end{array}$ & $\begin{array}{l}\text { Testing user-centered } \\
\text { interoperability, } \\
\text { compatibility of platforms/ } \\
\text { OS/browsers, and client } \\
\text { technologies on a cloud }\end{array}$ & $\begin{array}{l}\text { Testing } \\
\text { application } \\
\text { compatibility, } \\
\text { end-to end } \\
\text { interoperability } \\
\text { and application } \\
\text { connectivity to } \\
\text { legacy systems. }\end{array}$ \\
\hline $\begin{array}{l}\text { Regression } \\
\text { Testing }\end{array}$ & $\begin{array}{l}\text { Changed \& impacted } \\
\text { SaaS/Cloud service features } \\
\text { and related APIs/ } \\
\text { connectivity }\end{array}$ & $\begin{array}{l}\text { Cloud/SaaS-oriented } \\
\text { regression testing inside } \\
\text { a cloud }\end{array}$ & $\begin{array}{l}\text { User-centered re-validation on a } \\
\text { cloud }\end{array}$ & $\begin{array}{l}\text { End-to-end } \\
\text { application } \\
\text { system regression } \\
\text { over clouds }\end{array}$ \\
\hline
\end{tabular}


Table 2. Cloud Testing Platforms [18,19,20,21,28]

\begin{tabular}{|c|c|c|}
\hline Platform & $\begin{array}{l}\text { Year of } \\
\text { Launch }\end{array}$ & Key Offerings \\
\hline Acutest & 2002 & $\begin{array}{l}\text { SAP performance } \\
\text { testing, load } \\
\text { testing, stress } \\
\text { testing }\end{array}$ \\
\hline LoadRunner & 2006 & $\begin{array}{l}\text { Load testing, } \\
\text { examining system } \\
\text { performance }\end{array}$ \\
\hline Soasta & 2006 & $\begin{array}{l}\text { TouchTest, } \\
\text { mPulse, cloud } \\
\text { testing }\end{array}$ \\
\hline $\begin{array}{c}\text { Amazon web } \\
\text { services }\end{array}$ & 2006 & $\begin{array}{l}\text { Infrastructure as a } \\
\text { service. }\end{array}$ \\
\hline $\begin{array}{l}\text { Google app } \\
\text { engine }\end{array}$ & 2008 & $\begin{array}{l}\text { Web Application } \\
\text { Platform as a } \\
\text { service }\end{array}$ \\
\hline Blue cloud & 2008 & $\begin{array}{l}\text { Virtualised Blue } \\
\text { cloud data centre }\end{array}$ \\
\hline Force.com & 2008 & $\begin{array}{l}\text { Proprietary 4GL } \\
\text { Web Application } \\
\text { framework. }\end{array}$ \\
\hline Loadstorm & 2008 & $\begin{array}{l}\text { Saas, } \\
\text { performance } \\
\text { testing, load } \\
\text { testing, stress } \\
\text { testing }\end{array}$ \\
\hline GoGrid & 2008 & $\begin{array}{l}\text { Hosting E } \\
\text { commerce, web } \\
2.0 \text { and web apps, } \\
\text { computing power }\end{array}$ \\
\hline Azure & 2009 & $\begin{array}{l}\text { Application } \\
\text { platform as a } \\
\text { service }\end{array}$ \\
\hline Heroku & 2010 & $\begin{array}{l}\text { Build modern } \\
\text { apps, PaaS. }\end{array}$ \\
\hline
\end{tabular}

\section{CLOUD TESTING CHALLENGES}

\subsection{Security challenge}

It is one of the major issues of cloud testing. As cloud testing is completely based on the internet, there are various threats of viruses, service disruption, no privacy of personal information, internet suspending, slow internet speed etc. Various procedures as virtual private clouds and client partitions are being developed for handling all such security issues [1,22]. As the information is travelling through the internet, firstly security testing is needed to be performed to check whether there is any data leakage or not. There are various sub challenges associated with this. First challenge deals with confidentiality of data, service disruption, slow internet speed and viruses attacks. Second challenge deals with meeting the security requirements as monitoring and maintaining the systems $[23,24]$.

\subsection{Lack of standards}

Another challenge in cloud testing is the lack of universal stands in public cloud environment. At present there are no suitable standard solutions which could help to integrate public cloud resources with user company's internal data centre resources. This tends to be a challenge in cases when companies want to switch vendors $[1,22,25]$.

\subsection{Infrastructure}

One another challenge is the limited infrastructure as only limited types of technology, configurations, storage and servers, networking and bandwidth are provided by cloud providers which make it difficult for creating real-time test environments [25].

\subsection{Usage}

If cloud based test environments are not used in a proper manner, this could eventually lead to increasing costs. For overcoming this challenge the companies should first improve their cost models and apply only process driven estimates.

\subsection{Planning of test environment}

Test environments should be carefully planned by the testing teams before putting them into the testing environments. Testing teams should analyse the expenses for avoiding over usage and over payment which would help to monitor the utilisation of cloud resources.

\subsection{Test data}

Test data should be adequately managed. For effective testing, testing tasks depends on customers. Customers are not allowed to supply confidential data to third parties due to some rules and regulations. Hence for testing in a cloud, test data is doubly scrutinized.

\subsection{SLA}

Service level agreements as some terms and conditions of cloud services are difficult to comprehend which include areas as data preservation, data integrity, data location and transfer.

\subsection{Performance}

Clouds are shared by various users at a time. Sometimes a sudden announcement of service disruption is done by the service provider due to low bandwidth or poor network. This could result in poor performance. This challenge can be resolved by working with the service provider.

\subsection{Service challenge}

It is known to be the fundamental challenge in cloud testing environment. It has some sub challenges. First challenge is service availability. Proper cloud services must be available at all times without any further delays. Second challenge is service assurance which means timely delivery of cloud services. And the third challenge is of service efficiency. It encourages efficiency from cost savings to cloud service delivery [16,27].

\subsection{Layered testing challenge}

It is the challenge which involves testing at several layers of cloud environment. The first challenge in this category is the layers testing protocol in which multiple layers are added to cloud testing by server performance, database and software applications $[24,26]$. Second challenge involves maintenance and testing of communication between layers and further planning for the risks $[25,26]$. 


\subsection{Guidance, knowledge and staff expertise}

Obtaining guidance, knowledge and expertise is another challenge. Guidance which has been used so far is not enough and is incomplete. There are still some areas where additional guidance is needed. Expertise staff is lacking in cloud service environment to implement cloud solutions. Acquiring direct knowledge has always been a challenge for delivering cloud services [24,27].

\section{CONCLUSION AND FUTURE DIRECTIONS}

Cloud testing is the most recent research topic among new researchers nowadays. As the Advance of testing as services and cloud technology, more research work must be done to address the open challenges and issues in cloud testing and TaaS. This paper provides a comprehensive Review on cloud testing by discussing the related concepts, issues, benefits and challenges. The major contributions of this paper include its intelligent discussion about cloud testing in terms of its requirements, benefits, and features. In future, as it is getting more matured architecture for cloud computing and more and more testing on the cloud applications there is every possibility of more testing challenges.

\section{REFERENCES}

[1] Jerry Gao, Xiaoying Bai \& W.T. Tsai, "Cloud TestingIssues, Challenges, Needs and Practice", Software Engineering: An International Journal, Vol. 1, No. 1, pp. 9-23, 2011

[2] Dr. Rahul Malhotra \& Prince Jain" Testing Techniques and its Challenges in a Cloud Computing Environment" The SIJ Transactions on Computer Science Engineering \& its Applications (CSEA), Vol.1, No. 3, pp. 88-93, July-August 2013.

[3] A.K. Srivastava, D. K. Yadav \& S. K. Pandey, "TaaS: An Evolution of Testing Services using Cloud Computing," International Journal of Advanced Research in Computer Engineering \& Technology (IJARCET), vol. 1, no. 10, pp. 42-49, 2012.

[4] Cloud Testing http://www.techopedia.com/definition/26540/cloudtesting.

[5] A.Vanitha Katherine \& Dr.K. Alagarsamy, "Conventional Software Testing Vs. Cloud Testing", International Journal of Scientific \& Engineering Research, Vol. 3, No. 9, pp. 1-5, 2012.

[6] Overview of Functional Testinghttp://en.wikipedia.org/wiki/Functional_testing\#cite_note -1 .

[7] Yatendra Singh Pundhir "Cloud Computing Applications and their testing methodology" Bookman International Journal of Software Engineering, Vol. 2 No. 1, pp. 1-4, Jan-Feb-Mar 2013

[8] Overview of System Testinghttp://en.wikipedia.org/wiki/System_testing.

[9] Lalit Kumar, Dr. Gurdev Singh \& Prince Jain, "Cloud Implementation and Cloud Integration", International
Journal of Computers \& Technology, Vol. 2, No. 1, pp. $1-5,2012$

[10] Overview of Testing in Cloud By Kulamani Sahoo, 18 Apr 2013.

[11] V. Prakash \& S. Gopalakrishanan, "Cloud Computing Solution - Benefits and Testing Challenges" Journal of Theoretical and Applied Information Technology, Vol. 39 No.2, pp. 114-118, 15 May 2012.

[12] Keerti Kulkarni, "Testing Services through Cloud”, A White Paper, MicroFocus.

[13] Cloud

Security

Testinghttp://www.toolsjournal.com/testing-lists/item/404-10cloud- based-testing-tools.

[14] Eljona Proko \& Ilia Ninka, "Analysis and Strategy for the Performance Testing in Cloud Computing", Global Journal of Computer Science and Technology Cloud \& Distributed, Vol. 12, No. 10, Version 1.0, pp. 11-14, 2012, USA

[15] Overview of Compatibility Testinghttp://en.wikipedia.org/wiki/Compatibility_testing.

[16] IXIA (2011), "Testing the Cloud: Definitions, Requirements and Solutions", August 2011, CA, URL http://www.ixiacom.com/.

[17] Neha Mehrotra (2011), "Cloud Testing Vs Testing a Cloud”, Infosys Viewpoint.

[18] Borko Furht, "Handbook of Cloud Computing" Lakshmanan, G. (April 2009). Cloud computing Relevance to enterprise. Infosys White Paper.

[19] Load-Storm: Load Storm Cloud Testing Services, Url:http://www.loadstorm.com.

[20] SOASTA, Inc., Soasta, Inc Cloud Testing Services, Url:http://www.soasta.com.

[21] Acutest, Acutest Cloud Testing Services, Url: http://www.acutest.co.uk.

[22] Cognizant reports - Taking testing to the Cloud, March 2011.

[23] S. Ravichandran, "Innovative Method of Software Testing Environment using Cloud Computing Technology", International Journal of Communication and Networking System, Vol. 01, No. 01, pp. 27-36, 2012.

[24] Swapnil H. Chandane \& Prof. Mahip M. Bartere, "New Computing Paradigm: Software Testing in Cloud, Issues, Challenges and Need of Cloud Testing in Today's World", International Journal of Emerging Research in Management \& Technology, pp. 68-75, 2013.

[25] Laurin H. Mills, "Legal Issues Associated with Cloud Computing", 2009.Priyanka, Inderveer Chana \& Ajay Rana, "Empirical Evaluation of Cloud-based Testing Techniques: A Systematic Review", ACM SIGSOFT Software Engineering Notes, Vol. 37, No. 3, pp. 1-9, 2012.

[26] Pat Hyek," Cloud Computing Issues and Impacts", Global Technology Industry Discussion Series, 2011.

[27] Cloud Testing Platform- https://www.heroku.com/. 